Te Ma, Tetsuya Inagaki, Mayuka Ban and Satoru Tsuchikawa*

\title{
Rapid identification of wood species by near-infrared spatially resolved spectroscopy (NIR-SRS) based on hyperspectral imaging (HSI)
}

https://doi.org/10.1515/hf-2018-0128

Received June 5, 2018; accepted October 19, 2018; previously published online December 13, 2018

\begin{abstract}
Conventional near-infrared (NIR) spectroscopy has shown its potential to separate wood species nondestructively based on the aggregate effect of light absorption and scattering values. However, wood has an aligned microstructure, and there is a large refractive index (RI) mismatch between the wood cell wall substance $(n \approx 1.55)$ and the cell lumen (air $\approx 1.0$, water $\approx 1.33$ ). Light scattering is dominant over absorption $\left(\mu_{s}^{\prime} \gg \mu_{a}\right)$ in wood, and this fact can be utilized for complex classification purposes. In this study, an NIR hyperspectral imaging (HSI) camera combined with one focused halogen light source $(\varnothing 1 \mathrm{~mm})$ was designed to evaluate the light scattering patterns of five softwood (SW) and 10 hardwood (HW) species in the wavelength range from 1002 to $2130 \mathrm{~nm}$. Several parameters were combined to improve the data quality, such as image histogram plots of defined spaced bins (associated with diffuse reflectance values of light), variance calculation on the frequency (the number of pixels in each bin) of each histogram and the principal component analysis (PCA) of all the variance values at each wavelength. The identification accuracy of the quadratic discriminant analysis (QDA) under the five-fold cross-validation method was $94.1 \%$, based on the first three principal component (PC) scores.
\end{abstract}

Keywords: halogen spot-light source, hardwood, light scattering characteristics, near-infrared hyperspectral imaging camera, principal component analysis (PCA), quadratic discriminant analysis (QDA), softwood, spatially resolved spectroscopy, wood species identification

\footnotetext{
*Corresponding author: Satoru Tsuchikawa, Graduate School of Bioagricultural Sciences, Nagoya University, Furo-Cho, Chikusa, Nagoya 464-8601, Japan, e-mail: st3842@agr.nagoya-u.ac.jp Te Ma, Tetsuya Inagaki and Mayuka Ban: Graduate School of Bioagricultural Sciences, Nagoya University, Furo-Cho, Chikusa, Nagoya 464-8601, Japan
}

\section{Introduction}

With the high diversity of species, wood identification is extremely important in the modern wood industry and for monitoring the timber trade. However, wood identification based on macroscopic characteristics alone is not always possible (Toscano et al. 2015). Consideration of microscopic features can be very helpful in this regard (Alfonso et al. 1989; Baas et al. 2004), and nowadays, DNA barcoding differences may contribute to this task (Ohyama et al. 2001). Most of the methods are time-consuming and require special knowledge and in-depth training in wood histology and wood anatomy systematics (Lang et al. 2015). Automatic identification systems would have great advantages in fields of wood recycling and monitoring illegal logging and the trade in protected tree species.

Near-infrared (NIR) spectroscopy has proven to be powerful for the analysis of the properties of wood over the past two decades. In the range of $800-2500 \mathrm{~nm}$, there are numerous overtone and combination bands of vibrational frequencies due to functional groups, such as $\mathrm{C}-\mathrm{H}, \mathrm{O}-\mathrm{H}$ and $\mathrm{N}-\mathrm{H}$. It is possible to detect these differences on objects at wavelengths that are not visible to the naked eye. Rapid quantitative evaluation can be achieved by analyzing light reflectance or transmittance values without special pre-treatments of the sample (Yao and $\mathrm{Pu}$ 2009; Leblon et al. 2013; Tsuchikawa and Kobori 2015). The overlapping NIR bands appear non-specific and poorly resolved, but they can be evaluated well by multivariate calibration algorithms and statistical methods (chemometrics), such as principal component regression (PCR) and partial least squares (PLS) regression analysis (Martens and Naes 1989).

Studies involving the use of NIR spectroscopy in discriminating between wood species are not common, but Tsuchikawa et al. (2003) combined NIR spectroscopy and the Mahalanobis distance to discriminate various wood samples (Cryptomeria japonica, Pseudotsuga menziesii, Picea sitchensis, Tectona grandis, Quercus mongolica, Paulownia tomentosa, Quercus gilva, Fagus crenata) with various moisture contents (MCs). Pastore et al. (2011) combined NIR spectroscopy and PLS-discriminant analysis 
(PLS-DA) to discriminate Swietenia macrophylla from three similar kinds of wood species (Carapa guianensis, Cedrela odorata, and Micropholis melinoniana). Abe et al. (2015) achieved a successful separation between five softwood (SW: Chamaecyparis obtusa, Cryptomeria japonica, Sciadopitys verticillata, Thujopsis dolabrata, Torreya nucifera) and five hardwood (HW: Aesculus turbinata, Cercidiphyllum japonicum, Cinnamomum camphora, Prunus jamasakura, Zelkova serrate) species by NIR spectroscopy combined with the principal component analysis (PCA) method. The quoted authors concluded that the chemical component differences (mainly hemicelluloses and lignin) between the SW and HW species contribute much to the classification. Abe et al. (2016) were also successful in differentiating between two SW species (Chamaecyparis obtusa, Torreya nucifera). The results indicated that light-transmitting properties inside wood might be used for wood species classification with advanced measurement systems, especially in combination with mathematical data evaluation. Wood as a "turbid biological material" exhibits an anisotropic light propagation behavior because of its complex microstructure. Light absorption is primarily related to chemical components, whereas light scattering is influenced mainly by physical characteristics, but the conventional NIR spectroscopy cannot differentiate between these two effects (Qin and Lu 2008). There are encouraging observations that light scattering patterns could be useful for wood species classification.

In the present paper, an NIR hyperspectral imaging (HSI) camera combined with a focused halogen light source $(\emptyset 1 \mathrm{~mm})$ working in the in-line scanning mode was applied to acquire spatially resolved reflectance images $(1002-2130 \mathrm{~nm})$ of wood samples. The expectation was that the light scattering characteristics of wood would be able to differentiate between five SWs and $10 \mathrm{HWs}$, while the HWs comprise both ring-porous and diffuse-porous species. Such a spatially resolved imaging-based technique has not yet been described in the literature and thus we expect new insights in the field of rapid and automatic wood species identification.

\section{Materials and methods}

Sample preparation: The wood was commercially purchased from a local wood processing company including five SW species: agathis (Agathis alba), Norfork island pine (Araucaria heterophylla), western red cedar (Thuja plicata), hinoki cypress (Chamaecyparis obtusa) and Japanese cedar (Cryptomeria japonica), and $10 \mathrm{HW}$ species: ayous (Triplochiton scleroxylon), balsa (Ochroma pyramidale), rubber tree (Hevea brasiliensis), yellow poplar (Liriodendron tulipifera), katsura tree (Cercidiphyllum japonicum), empress tree (Paulownia tomentosa), castor aralia (Kalopanax pictus), Manchurian ash (Fraxinus mandshurica), ulin (Eusideroxylon zwageri) and European beech (Fagus sylvatica). Three air-dried samples with the dimensions of $12 \mathrm{~mm}(\mathrm{~T}) \times 30 \mathrm{~mm}(\mathrm{~L}) \times 80 \mathrm{~mm}(\mathrm{R})$ were prepared. The cellular structure was significantly different between earlywood (EW) and latewood (LW), especially for SWs. Therefore, only the EW areas were studied. However, in several HWs (beech, katsura tree, etc.), the EW

Table 1: Air-dry densities and moisture contents of the 15 wood sample species (average data with SD).

\begin{tabular}{lrrl}
\hline Name & Density $\left(\mathrm{g} \mathrm{cm}^{-3}\right)$ & MC (\%) & DP RP \\
\hline Softwoods & & & \\
Agathis & $0.45 \pm 0.00$ & $10.29 \pm 0.20$ & \\
Norfork island pine & $0.47 \pm 0.00$ & $11.31 \pm 1.23$ & \\
Western red cedar & $0.35 \pm 0.01$ & $10.03 \pm 0.10$ & \\
Hinoki cypress & $0.45 \pm 0.01$ & $10.04 \pm 0.22$ & \\
Japanese cedar & $0.39 \pm 0.00$ & $10.78 \pm 0.30$ & \\
Hardwoods & & & \\
Ayous & $0.45 \pm 0.00$ & $9.73 \pm 0.10$ & DP \\
Balsa & $0.14 \pm 0.00$ & $8.63 \pm 0.19$ & DP \\
Rubber tree & $0.67 \pm 0.01$ & $8.69 \pm 0.23$ & DP \\
Yellow poplar & $0.45 \pm 0.00$ & $8.42 \pm 0.11$ & DP \\
Katsura tree & $0.52 \pm 0.01$ & $8.97 \pm 0.15$ & DP \\
Beech & $0.67 \pm 0.00$ & $8.91 \pm 0.10$ & DP \\
Ulin & $1.09 \pm 0.00$ & $8.59 \pm 0.13$ & DP \\
Castor aralia & $0.52 \pm 0.01$ & $7.62 \pm 0.13$ & RP \\
Manchurian ash & $0.57 \pm 0.00$ & $9.47 \pm 0.18$ & RP \\
Empress tree & $0.28 \pm 0.00$ & $8.74 \pm 0.17$ & RP \\
\hline
\end{tabular}

DP, diffuse-porous; RP, ring-porous; MC, moisture content; SD, standard deviation.

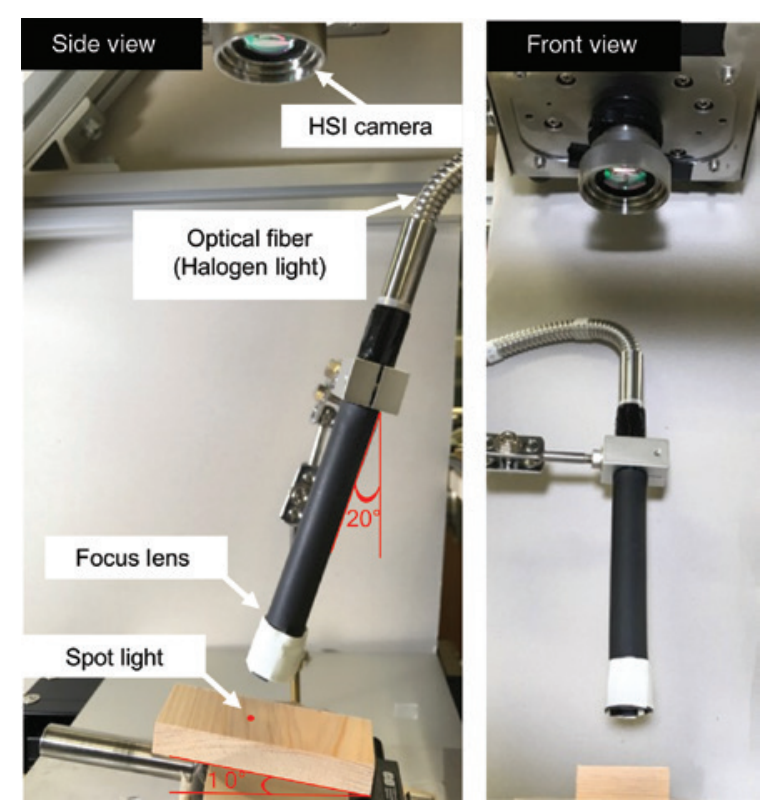

Figure 1: A spatially resolved image measurement system was designed, mainly including an NIR-HSI camera and a focused halogen light source at $\emptyset 1 \mathrm{~mm}$. 
and HW were difficult to detect because the fiber diameter did not change during the growing season. In such cases, the light-colored surface area was measured. Table 1 shows the density and MC of the species in the winter season.

Microscopic observations: Microscopic images were taken to check the different wood cell wall structures, which directly contribute to distinctive light scattering characteristics. Briefly, a small part of each wood species was sliced by a microtome, then dyed with safranin solution for cross-sectional microscopic imaging $(2560 \times 1920$ pixels corresponding to $1.12 \times 0.84 \mathrm{~mm}$ ) under a bright-field microscope (PrimoStar, Carl Zeiss Microscopy Co., Tokyo, Japan).

NIR spatially resolved spectroscopy (NIR-SRS): The NIR-HSI system (Compovision, Sumitomo Electric Industries, Ltd., Osaka, Japan) was calibrated both spectrally and spatially. The camera possesses a spectroscope and a two-dimensional (2D) InGaAs detector [256 pixels (spectral information) $\times 320$ pixels (spatial information)] that can receive NIR light in the range of $913-2519 \mathrm{~nm}$, at a spectral interval of ca. $6.2 \mathrm{~nm}$. The distance between the target and the camera was manually adjusted to achieve a horizontal field of view of $60 \mathrm{~mm}$ with a spatial interval of $187.5 \mu \mathrm{m}$. The NIR-HSI system operated in the vertical plane with the specimen directly below. A concentrated point light source, derived from a halogen lamp focused to a $\emptyset 1 \mathrm{~mm}$ spot, was set up on one side of the imaging lens, at $20^{\circ}$ from the vertical plane. Thus, to collect the reflected light properly, the samples were adjusted to a slope of $10^{\circ}$ from the horizontal plane. Each sample and the light fiber were fixed on a slider and scanned for light scattering area line-by-line in a push-broom manner (Figure 1). The same NIRHSI system was described by Ma et al. (2018). The frame rate was set
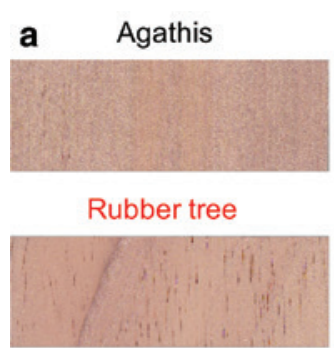

Castor aralia

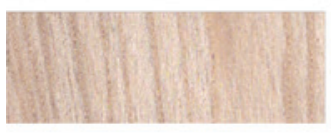

b

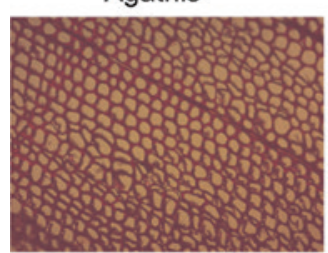

Rubber tree
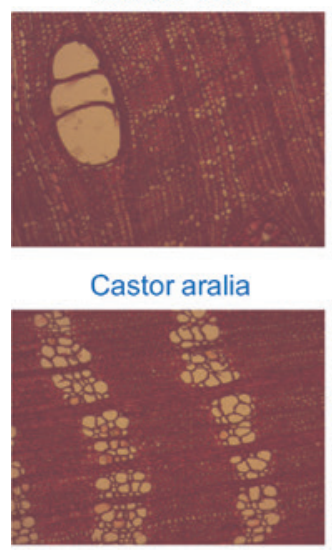

Norfork island pine

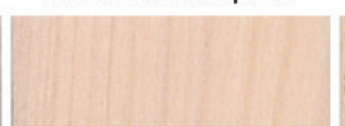

Hinoki cypress

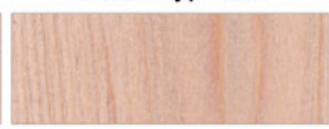

Japanese ceder

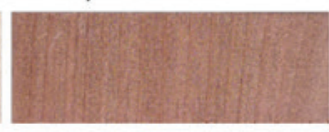

Norfork island pine

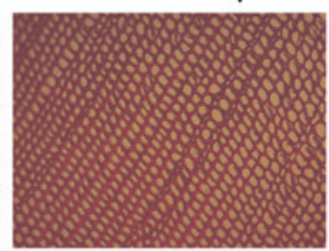

Hinoki cypress

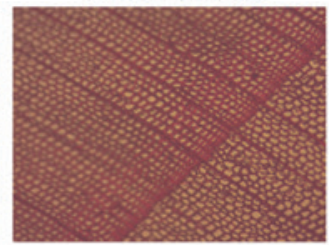

Japanese ceder

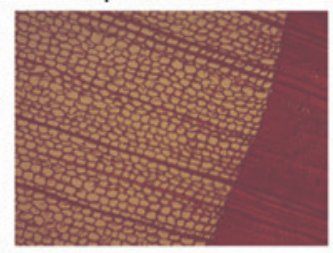

Ayous

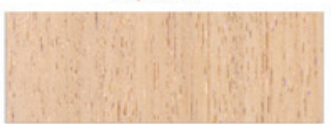

Yellow poplar

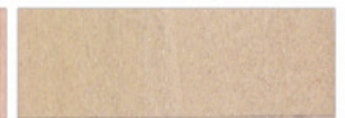

Manchurian ash

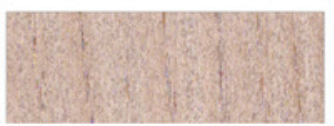

Ayous

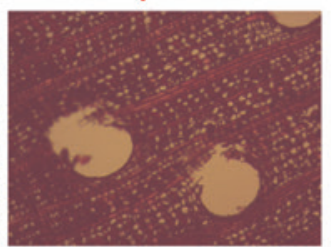

Yellow poplar

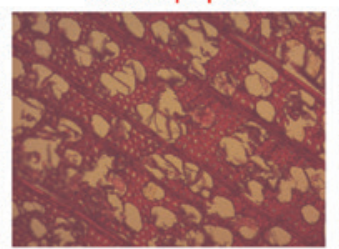

Manchurian ash

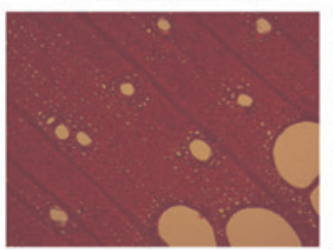

Balsa

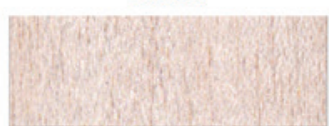

Katsura tree

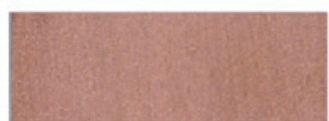

Ulin

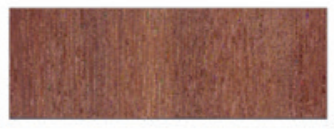

Balsa

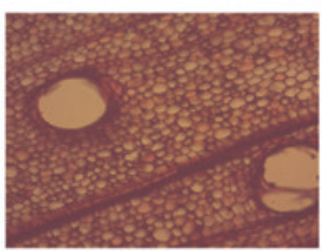

Katsura tree
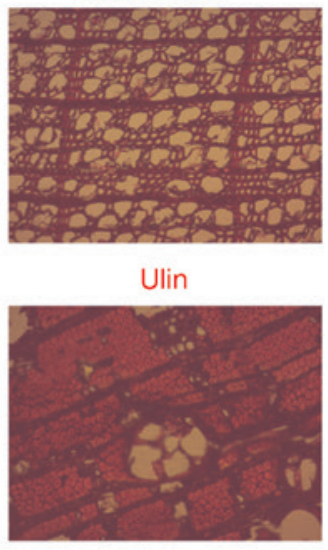

Western red cedar

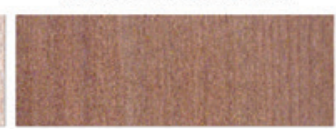

Empress tree

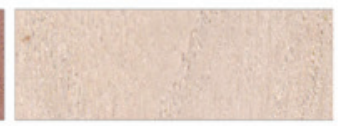

Beech

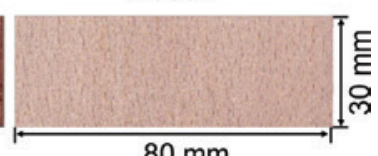

$80 \mathrm{~mm}$

Western red cedar

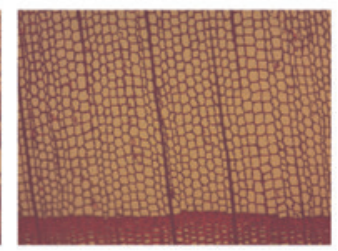

Empress tree
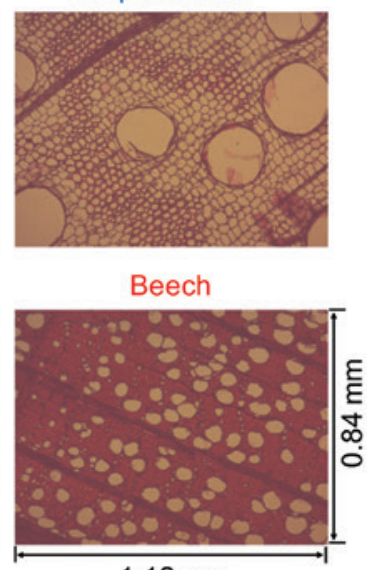

$1.12 \mathrm{~mm}$

Figure 2: (a) Cross-grained surface (measured) of the 15 wood sample species. (b) Microscopic images of the 15 wood sample species. Softwoods (black title) are much simpler with more periodic anatomical features than hardwoods (red title: diffuse-porous and blue title: ring-porous). Overall, each sample structure is unique from the other. It contributes to distinctive light scattering characteristics. 
to 200 frames s $\mathrm{s}^{-1}$. Overall, three randomly selected positions within the EW part of the samples were scanned separately. As a reference, a white plate was imaged under the same conditions, and a dark image was obtained by turning off the light source and completely covering the lens with its cap. Light illumination center values of the white plate were copied for matching the same area as the sample measured data. All the collected spectral images of the wood samples were then converted to relative reflectance values according to the following equation:

$$
R_{\lambda, n}=\left(S_{\lambda, n}-D_{\lambda, n}\right) /\left(B_{\lambda, n}-D_{\lambda, n}\right),
$$

where $\lambda$ and $n$ are the wavelength and pixel index variables, respectively, $R_{\lambda, n}$ is the standardized light reflectance value at wavelength $\lambda$ and pixel $n$. $S_{\lambda, n}$ and $B_{\lambda, n}$ denote sample and white reference images, and $D_{\lambda, n}$ stands for dark image.

Selection of wavelength range: NIR-SRS provides a large number of variables (256 spectral images at equally spaced wavelengths from 913 to $2519 \mathrm{~nm}$ in this study). Wavelengths under $1002 \mathrm{~nm}$ and over $2130 \mathrm{~nm}$ were found to be noisy and unreliable, and so they were removed from the data set first.

Contour plot of each SRS image: The spatial distribution characteristics of incident light are related to wood cellular structure. In a radial plane, the scattering pattern of the incident light has an oval shape because wood is a semi-specular material that reflects part of the light directly at the surface, but a part of the light penetrates the surface, which is scattered in the material (Nyström 2003). There is a large RI mismatch between the wood cell wall substance $(n \approx 1.55)$ and the cell lumen (air $\approx 1.0$, water $\approx 1.33$ ). Thus, multiple reflections of light may occur on the repetitive wood cell wall substance-air boundary, which results in an illuminated spotlight conducted by the fiber layers. In addition, light propagated across the wood cell wall is attenuated more than that in the cell lumen and eventually forms as an oval shape in a longitudinal direction of the fibers. Contour plots were used to display the three-dimensional (3D) relationship of each SRS image. Totally, 10 isolines $(0.01,0.03,0.05,0.07,0.09,0.2$, $0.4,0.6,0.8$ and 1.0) were drawn by connecting the image pixel (x-y coordinate), where the same diffuse reflectance of the incident light occurs.

Variance calculation in the areas between the isolines: Histogram plots along with the indicated isolines were generated as spaced bins to cover the range of elements (number of pixels). Then, the variance of the frequency data from each histogram was calculated and considered to represent the light spatial distribution characteristics instead of the individual SRS images.

Dimension reduction of the variance data: PCA (Martens and Naes 1989) was performed to reduce the variance data dimensions [input data: 180 variance values at independent wavelengths; output data: principal component (PC) scores] to improve the efficiency and robustness of the statistical analysis.

Wood species identification: The prediction stability for separating 15 species based on the first three PC scores was evaluated by quadratic discriminant analysis (QDA), combined with five-fold cross-validation, while the original sample was randomly partitioned into five equal-sized subsamples, four subsamples for training a classification model and a single subsample for testing the model. The cross-validation process was repeated 5 times. QDA is a probabilistic parametric classification technique and assumes a quadratic decision boundary that is used in situations in which there is a clear separation among the classes (Hastie et al. 2009). In addition, a broader

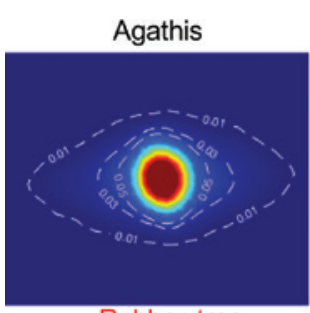

Rubber tree

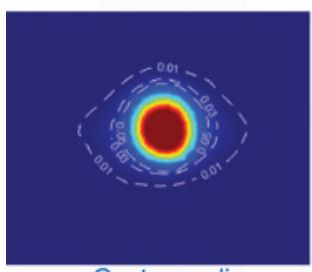

Castor aralia

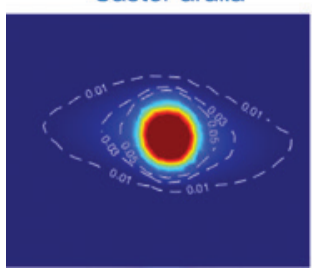

Norfork island pine

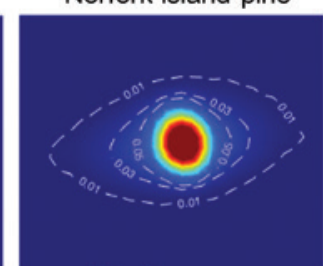

Hinoki cypress

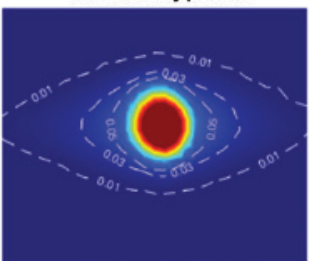

Japanese ceder

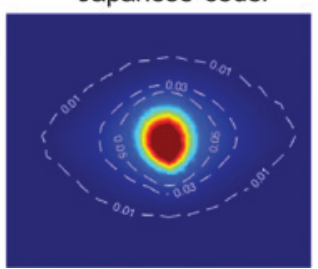

Ayous

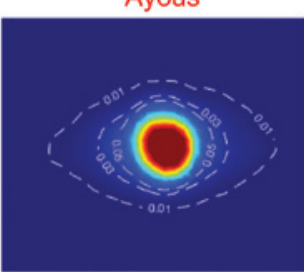

Yellow poplar

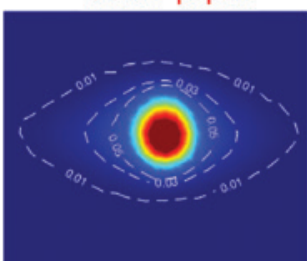

Manchurian ash

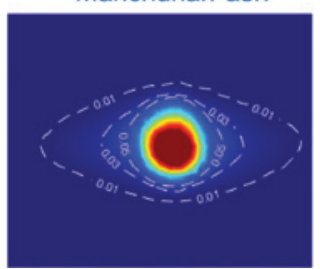

Balsa

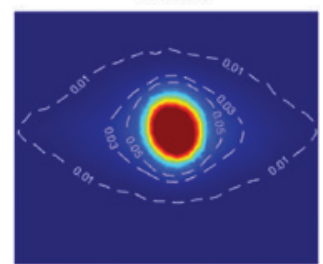

Katsura tree

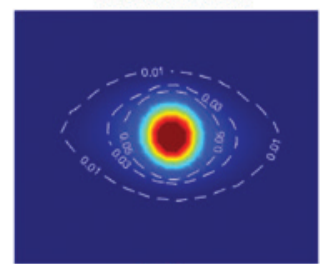

Ulin

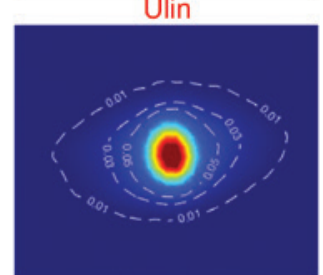

Western red cedar

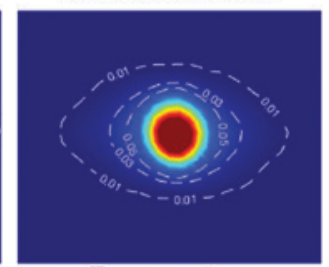

Empress tree

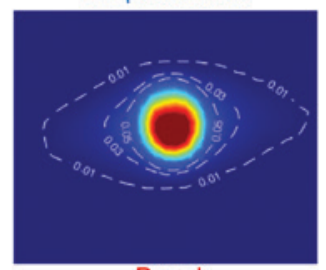

Beech

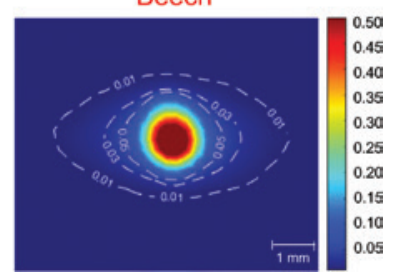

Figure 3: NIR-SRS images of the 15 species at a wavelength of $1312 \mathrm{~nm}$. Light scattering pattern differences are evident.

For example, wood samples (rubber tree, ulin and beech) with higher density, presenting the results with smaller light scattering patterns. 
range of problems can be more accurately modeled by QDA than by the linear discriminant analysis (LDA). Matlab (The Mathworks, Inc., Natick, MA, USA) was used for data analysis.

\section{Results and discussion}

Figure 2a shows the measured cross-grained surface of the 15 species (black title: SW, red title: diffuse-porous HW and blue tile: ring-porous HW). Figure $2 \mathrm{~b}$ shows the representative microscopic images. SWs have more periodic anatomical features than HWs, while the longitudinal tracheids constitute about $90 \%$ of the volume of the SW. On the other hand, HWs dispose of large diameter vessels for fluid conduction. The microstructure of each microstructure is unique. Not only the cell wall area rate but also the structure shape variances would cause differences in the light scattering patterns. Kitamura et al. (2016) pointed out that the wood cell wall scatters light, but with increasing median pore area, multiple reflections may occur on the repetitive wood cell wall and air boundaries, which reduces the transmitted light intensity.

Figure 3 shows representative SRS images at $1312 \mathrm{~nm}$ collected from the EW part of each wood species. Several studies evaluated the grain angle via the light scattering patterns (Zhou and Shen 2003; Hu et al. 2004; Simonaho et al. 2004). In addition, wood samples (e.g. rubber tree, ulin and beech) with a higher density (with higher cell wall-to-area ratio) show results with smaller light scattering patterns. A further observation was that in the HW or SW groups (where the main chemical substances were similar), the light scattering pattern differences were still evident. If it would be possible to enhance these differences, a high accuracy in the wood species identification would be possible.

Figure 4 shows histogram plots of the SRS images (Figure 3) with the histogram functions $(0.01,0.03,0.05$,
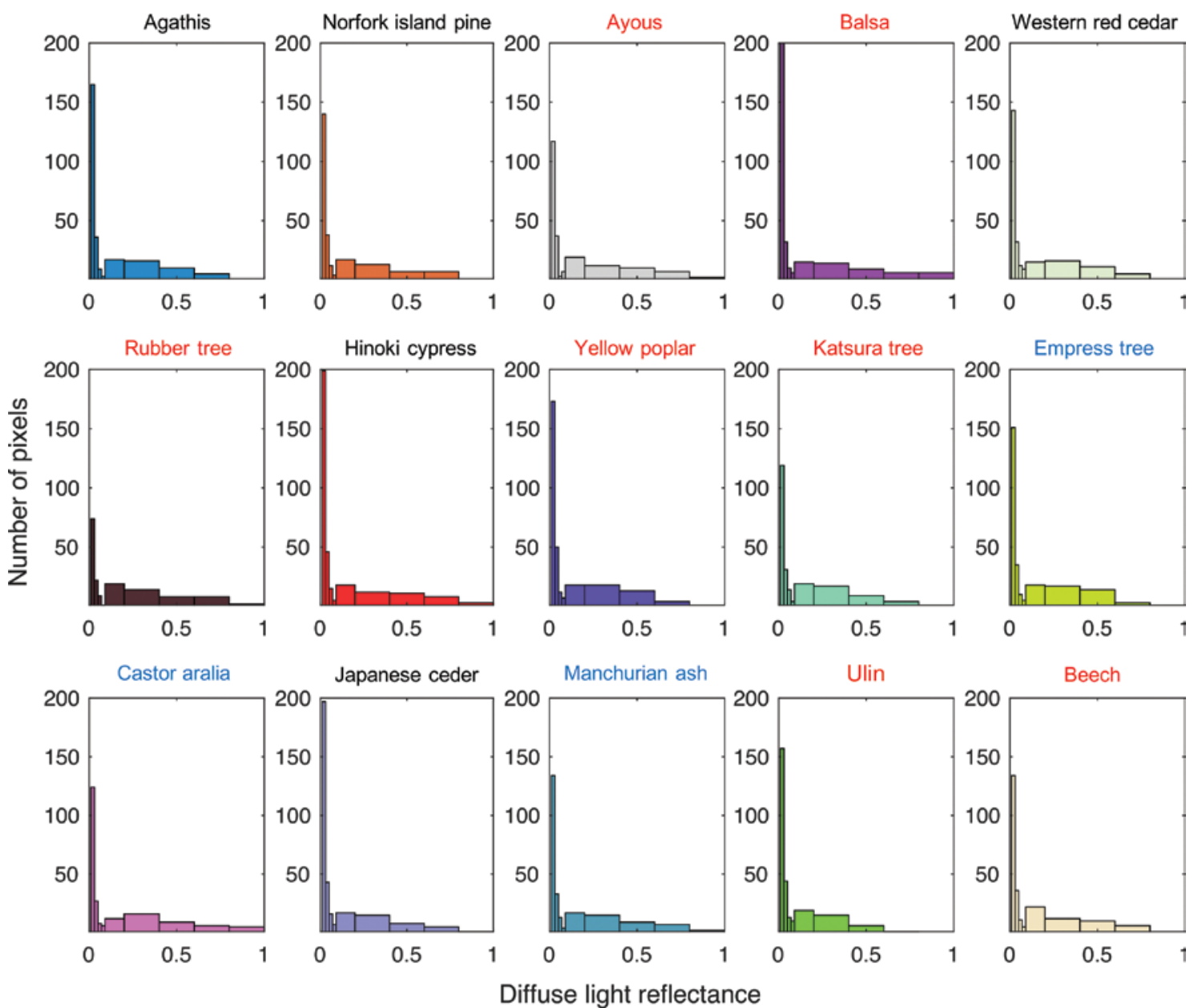

Figure 4: Image histogram plot of the SRS images shown in Figure 3.

The frequencies at lower light reflectance ranges $(0.01-0.03,0.03-0.05$, and $0.05-0.07)$ have apparent difference among the 15 wood species. 


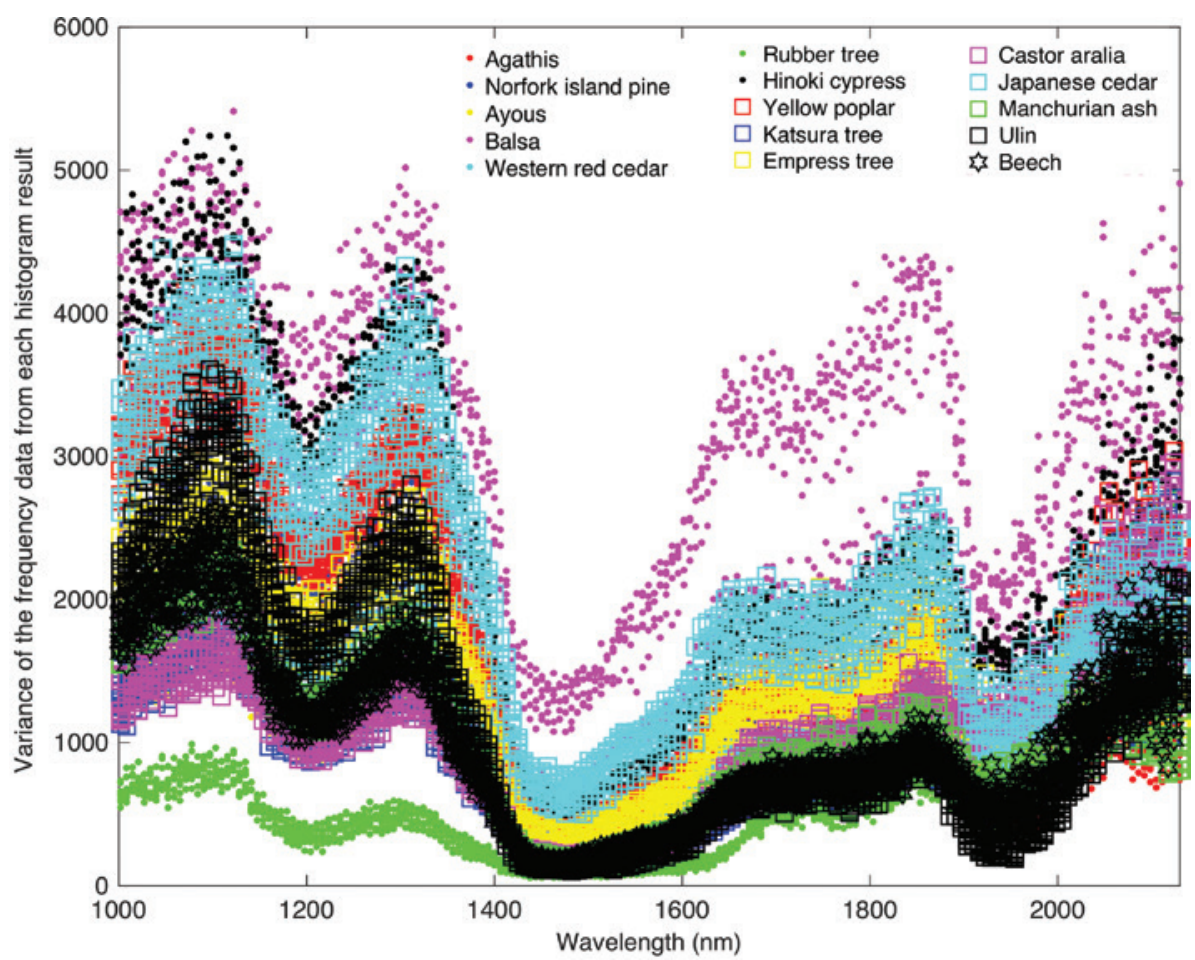

Figure 5: Variance data plot of the 15 wood sample species (NIR wavelength range is 1002-2130 nm, with a $6.2 \mathrm{~nm}$ interval). Each species include nine values at each independent wavelength. They were collected from three prepared samples and three different measurement positions of each sample (earlywood part).

0.07, 0.09, 0.2, 0.4, 0.6, 0.8 and 1.0) as placed bins with a non-uniform width, to reveal the underlying shape of the distribution. The bins appear as rectangles so that the rectangle heights represent the number of the image pixels.
The frequencies (number of pixels) at lower light reflectance ranges (0.01-0.03, 0.03-0.05 and 0.05-0.07) show apparent differences among the 15 wood species, which can also be seen in Figure 3.

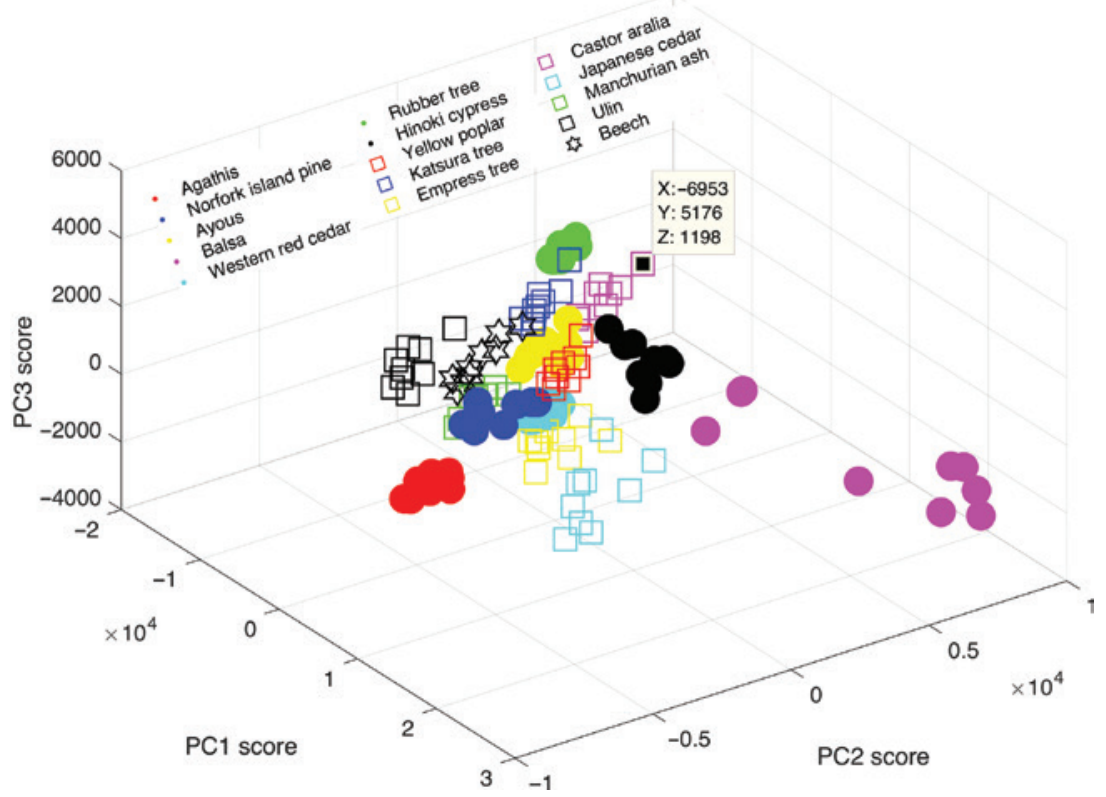

Figure 6: 3D scatter plot using the first three PC scores calculated from the total variance values. The differences among the 15 wood species can be clearly distributed. 
Figure 5 shows the plot of variances as calculated from the frequency of the histogram plots. The NIR wavelength range was from 1002 to $2130 \mathrm{~nm}$, with $6.2 \mathrm{~nm}$ intervals. Each species included nine values at each independent wavelength. They were collected from three prepared samples and three different measurement positions. The pixels with light reflectance values under 0.01 were ignored. Pronounced lower variance values were located at 1200, 1450 and $1920 \mathrm{~nm}$, which were attributed to C-H and $\mathrm{O}-\mathrm{H}$ group absorptions in wood.

Figure 6 shows the 3D scatter plot based on the first three PC scores. The 180 variance values at independent wavelengths are represented as numerical data based on the PC loadings. The accumulated contribution rate was 97.7\% (PC1: 85.7\%, PC2: 9.9\% and PC3: 2.1\%). The differences in the first three PC scores for each species can be clearly distributed.

The classification method was evaluated by QDA combined with a five-fold cross-validation. Figure 7 shows the detailed classification results with $94.1 \%$ cross-validation accuracy. It can be concluded that NIR-SRS-based HSI technique is fast and robust in separating the 15 wood species in the focus of this study.

\section{Conclusion}

Light scattering differences between wood species were studied for species identification. To this end, NIR-HSI were collected from a focused halogen light source $(\emptyset 1 \mathrm{~mm})$ and the images formed the basis for the evaluation of the light scattering characteristics of five SW and $10 \mathrm{HW}$ species. The unique cell wall structures of these species were manifested by different raw, spatially resolved images. The five-fold cross-validation accuracy was $94.1 \%$ of the image histogram plots, PCA of the frequency variances and QDA classification. The accuracy can be improved by repeating the same measurements on larger illuminated areas of the samples, which would reduce the spatial microstructure differences within the same species.

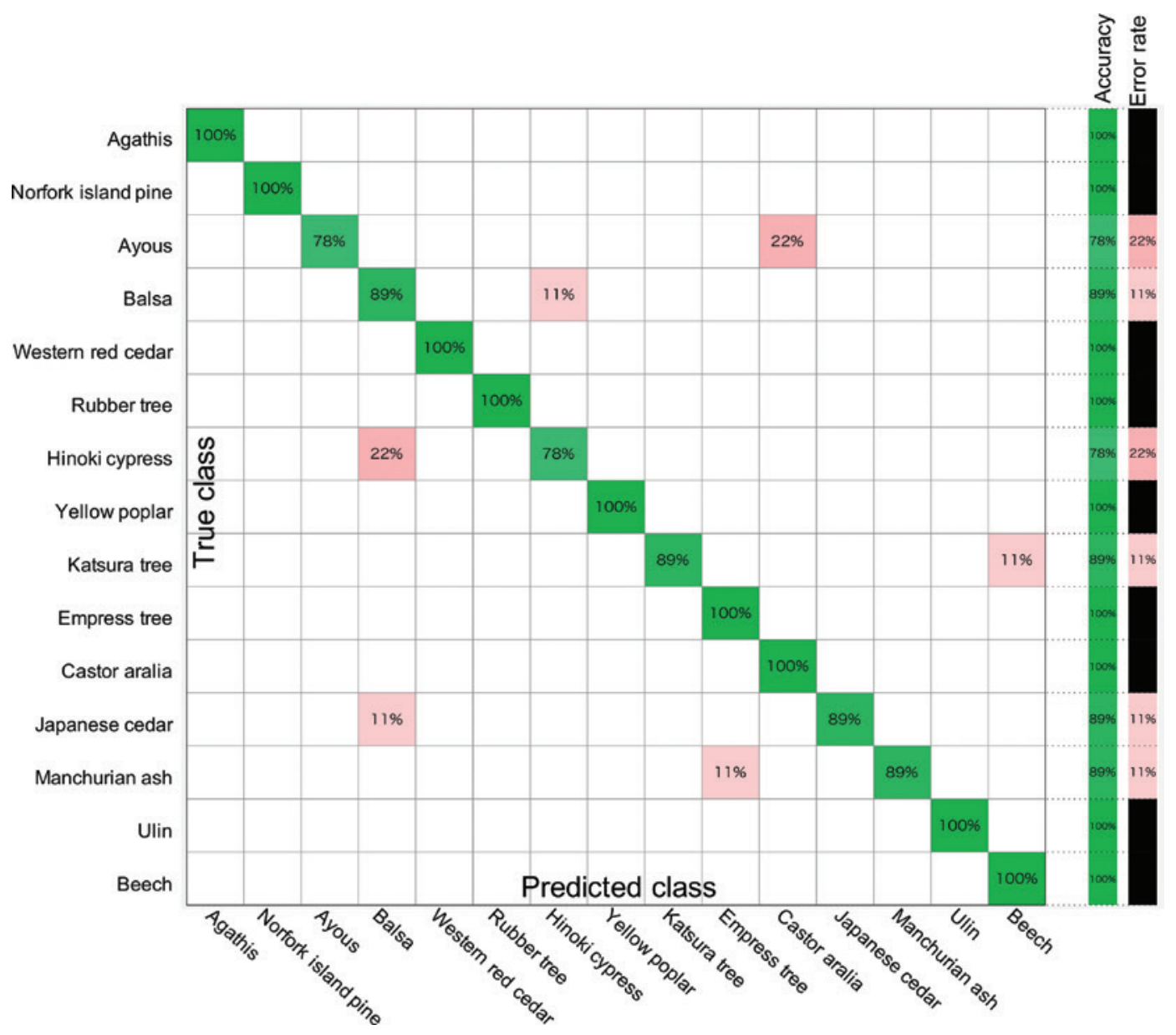

Figure 7: Mixing matrix between true class and predicted class: the prediction accuracy of nine species was $100 \%$, and other six species had little errors under QDA combined with the five-fold cross-validation method. 
Author contributions: All the authors have accepted responsibility for the entire content of this submitted manuscript and approved submission.

Research funding: The authors are grateful for the financial support provided by JSPS (KAKENHI, no. 25292102).

Employment or leadership: None declared.

Honorarium: None declared.

\section{References}

Alfonso, V.A., Baas, P., Carlquist, S., Chimelo, J.P., Coradin, V.T.R., Détienne, P., Gasson, P.E., Grosser, D., Ilic, J., Kuroda, K., Miller, R.B., Ogata, K., Richter, H.G., Welle, B.J.H., Whttler, E.A. (1989) IAWA list of microscopic features for hardwood identification. IAWA J. 10:219-332.

Abe, H., Watanabe, H., Ishikawa, A., Noshiro, S., Fujii, T., Iwasa, M., Kaneko, H., Wada, H. (2015) Non-destructive method for species identification of historical wooden statues using NIR spectroscopy: analysis using wood samples of the internationally authorized collection. Mokuzai Hozon (Wood Proteciton) 41:162-170.

Abe, H., Watanabe, H., Ishikawa, A., Noshiro, S., Fujii, T., Iwasa, M., Kaneko, H., Wada, H. (2016) Simple separation of Torreya nucifera and Chamaecyparis obtusa wood using portable visible and near-infrared spectrophotometry: differences in light-conducting properties. J. Wood Sci. 62:210-212.

Baas, P., Blokhina, N., Fujii, T., Gasson, P., Grosser, D., Heinz, I., Ilic, J., Jiang, X., Miller, R., Newsom, L.A., Noshiro, S., Richter, H.G., Suzuki, M., Terrazas, T., Wheeler, E., Wiedenhoeft, A. (2004) IAWA List of microscopic features for softwood identification. IAWA J. 25:1-70.

Hu, C., Tanaka, C., Ohtani, T. (2004) On-line determination of the grain angle using ellipse analysis of the laser light scattering pattern image. J. Wood Sci. 50:321-326.

Hastie, T., Tibshirani, R., Friedman, J. The Elements of Statistical Learning-Data Mining, Inference, and Prediction, Second Edition. Springer-Verlag, New York, 2009.

Kitamura, R., Inagaki, T., Tsuchikawa, S. (2016) Determination of true optical absorption and scattering coefficient of wooden cell wall substance by time-of-flight near infrared spectroscopy. Opt. Express. 24:3999-4009.

Leblon, B., Adedipe, O., Hans, G., Haddadi, A., Tsuchikawa, S., Burger, J., Stirling, R., Pirouz, Z., Groves, K., Nader, J., LaRocque, A. (2013) A review of near-infrared spectroscopy for monitoring moisture content and density of solid wood. Forest. Chron. 89:595-606.

Lang, C., Costa, F.R.C., Camargo, J.L.C., Durgante, F.M., Vicentini, A. (2015) Near infrared spectroscopy facilitates rapid identification of both young and mature Amazonian tree species. PLoS One 10:1-16.

Martens, H., Naes, T. (1989) Multivariate Calibration. Wiley, New York. 504 pages, ISBN: 047190979.

Ma, T., Schajer, G., Inagaki, T., Pirouz, Z., Tsuchikawa, S. (2018) Optical characteristics of Douglas fir at various densities, grain directions and thicknesses investigated by near-infrared spatially resolved spectroscopy (NIR-SRS). Holzforschung. 72:789-796.

Nyström, J. (2003) Automatic measurement of fiber orientation in softwoods by using the tracheid effect. Comput. Electron. Agr. 41:91-99.

Ohyama, M., Baba, K., Itoh, T. (2001) Wood identification of Japanese Cyclobalanopsis species (Fagaceae) based on DNA polymorphism of the intergenic spacer between trnT and trnL 5'exon. J. Wood Sci. 47:81-86.

Pastore, T.C.M., Braga, J.W.B., Coradin, V.T.R., Magalhães, W.L.E., Okino, E.Y.A., Camargos, J.A.A., De Muñiz, G.I.B., Bressan, O.A., Davrieux, F. (2011) Near infrared spectroscopy (NIRS) as a potential tool for monitoring trade of similar woods: discrimination of true mahogany, cedar, andiroba, and curupixá. Holzforschung 65:73-80.

Qin, J., Lu, R. (2008) Measurement of the optical properties of fruits and vegetables using spatially resolved hyperspectral diffuse reflectance imaging technique. Postharvest Biol. Technol. 49:355-365.

Simonaho, S.P., Palviaimen, J., Tolonen, Y., Silvennoinen, R. (2004) Determination of wood grain direction from laser light scattering pattern. Opt. Lasers Eng. 41:95-103.

Toscano, G., Duca, D., Rossini, G., Mengarelli, C., Pizzi, A. (2015) Identification of different woody biomass for energy purpose by means of soft independent modeling of class analogy applied to thermogravimetric analysis. Energy 83:351-357.

Tsuchikawa, S., Inoue, K., Noma, J., Hayashi, K. (2003) Application of near-infrared spectroscopy to wood discrimination. J. Wood Sci. 49:29-35.

Tsuchikawa, S., Kobori, H. (2015) A review of recent application of near infrared spectroscopy to wood science and technology. J. Wood Sci. 61:213-220.

Yao, S., Pu, J. (2009) Application of near infrared spectroscopy in analysis of wood properties. Spectrosc. Spect. Anal. 29: 974-978.

Zhou, J., Shen, J. (2003) Ellipse detection and phase demodulation for wood grain orientation measurement based on the tracheid effect. Opt. Lasers Eng. 39:73-89. 